\title{
POTENCIAL DE IMPLEMENTAÇÃO DA CERTIFICAÇÃO FLORESTAL NO POLO MOVELEIRO DE UBÁ ${ }^{1}$
}

\author{
Ricardo Ribeiro Alves ${ }^{2}$, Laércio Antônio Gonçalves Jacovine ${ }^{3}$, Márcio Lopes da Silva ${ }^{3}$, Sebastião Renato \\ Valverde $^{3}$, Áurea Maria Brandi Nardelli ${ }^{4}$ e José de Castro Silva ${ }^{3}$
}

\begin{abstract}
RESUMO - O trabalho objetivou avaliar o potencial de implementação da certificação florestal no polo moveleiro de Ubá, MG. Delimitaram-se, como objeto de estudo no polo, somente empresas ligadas à exportação, consideradas as potencialmente interessadas nessa certificação. Elaborou-se um questionário para buscar informações de seus produtos principais, incluindo composição, matéria-prima, fornecedores e mercado. Verificou-se que a maioria dessas empresas atendia principalmente ao mercado interno e suas exportações eram ocasionais. A matéria-prima utilizada, em geral, era de painéis reconstituídos, já certificados por muitos dos seus fornecedores. Em torno de $85 \%$ das empresas pesquisadas já atendiam plena ou parcialmente à política de porcentagens do FSC, vigente atualmente. Conclui-se que a certificação florestal pode ser considerada viável, visto que muitas das empresas já adquirem matéria-prima certificada, além do fato de que suas exportações têm aumentado, atingindo, assim, um mercado que exigirá essa certificação em breve.
\end{abstract}

Palavras-chave: Cadeia de custódia, exportação, FSC e mercado moveleiro.

\section{POTENTIAL OF IMPLEMENTING FOREST CERTIFICATION FOR UBA FURNITURE CENTER}

\begin{abstract}
This work aimed to evaluate the potential of implementing forest certification in the furniture center region of Ubá, MG. Only export companies, considered potentially interested in this type of certification, were selected for this study. A questionnaire was elaborated to obtain information on their main products, including composition, raw material, suppliers and market. The majority of these companies supplied the domestic market and exportation was an occasional activity. The raw material used was, in general, reconstituted panels that had been previously certified by its suppliers. Around $85 \%$ of the companies studied fully or partially met the currently effective FSC percentage policy. It was concluded that forest certification can be considered viable, since many of the companies already acquire certified raw material. Besides, their export activities has increased, soon reaching a market which will certainly demand this certification.
\end{abstract}

Keywords: Chain-of-custody, export, FSC and furniture market.

\section{INTRODUÇÃO}

Segundo dados da Abimóvel (2004), referentes a 2002, verificou-se que quatro estados brasileiros (SC, RS, PR e SP) respondiam por cerca de $93,6 \%$ da exportação de móveis do país. De acordo com Alves (2005), esses mesmos estados também eram os que possuíam maior número de certificação de cadeia de custódia para a indústria moveleira nacional e, juntos, perfaziam $82,15 \%$ do total certificado, nessas condições.

Sobre a certificação florestal, Garlipp (2001) citou que ela representa um dos importantes gargalos para a competitividade da indústria brasileira de madeira e móveis no mercado externo, pois as exigências da certificação do manejo florestal sustentável e da origem

\footnotetext{
${ }^{1}$ Recebido em 17.09.2007 e aceito para publicação em 06.03.2009.

${ }^{1}$ Pesquisa financiada pela FAPEMIG.

${ }^{2}$ Programa de Pós-Graduação em Ciência Florestal da Universidade Federal de Viçosa (UFV). E-mail: <ricardo.alves@ufv.br>.

${ }_{3}^{3}$ Departamento de Engenharia Florestal da UFV.E-mail: <jacovine@ufv.br>, <marlosil@ufv.br>, <valverde@ufv.br>, <jcastro@ufv.br>.

${ }^{4}$ Doutora em Ciência Florestal, auditora e revisora técnica do Grupo SGS nas áreas de Sustentabilidade e de Mudanças Climáticas.
} 
da matéria-prima ganham espaço e criam "padrões de mercado", como consequência da pressão de organizações ambientalistas e de grupos de compradores e varejistas, especialmente na Europa e nos Estados Unidos. Dessa forma, a obtenção de certificação florestal constitui, também, fator de competitividade para a indústria moveleira, principalmente quando esta se lança ao mercado externo.

Ainda que de forma incipiente, a indústria moveleira tem buscado a certificação florestal. Os custos do processo de obtenção da certificação na indústria moveleira, bem como a utilização da logomarca FSC pelas empresas e o grau de atendimento, importância e satisfação das empresas moveleiras certificadas, foram estudados por Jacovine et al. (2006a). Já a visão gerencial e estratégica que as empresas moveleiras têm da certificação florestal foi abordada por Jacovine et al. (2006b). No Polo Moveleiro de Ubá, onde não há empresa certificada, foi avaliado o grau de conhecimento que suas empresas possuem a respeito da certificação, como se comporta o seu mercado consumidor e quais as perspectivas de seus empresários com relação à obtenção da certificação florestal (ALVES et al., 2007).

As empresas moveleiras certificadas têm foco no mercado externo, cujos consumidores possuem consciência ambiental mais apurada e já exigem essa certificação. Por ser um instrumento de mercado, afirmaram Nardelli e Griffith (2003), a principal motivação das empresas em aderir aos padrões da certificação tem sido as oportunidades de negócios, pois, segundo Suiter Filho (2000), o mercado para produtos florestais ou confeccionados com matériaprima florestal oriundos de florestas bem manejadas e certificadas está em expansão.

Essas empresas moveleiras certificadas estão concentradas, principalmente, nos polos moveleiros brasileiros com maior participação na exportação, notadamente os da Região Sul do país e, também, no Estado de São Paulo.

Nos outros polos, mais direcionados ao mercado interno brasileiro, a certificação florestal é mínima, ou inexistente, pois não há motivação de mercado para se empreender um projeto dessa natureza. Todavia, alguns deles têm começado, mesmo que timidamente, a efetuar vendas para outros países, como é o caso do polo moveleiro de Ubá. Nos últimos anos, esse polo começou sua exportação por meio de um consórcio, formado por algumas poucas empresas. A participação em feiras nacionais de móveis e a realização da sua própria, a FEMUR (antiga Feira de Móveis de Ubá e Região e que atualmente chama-se de Feira de Móveis de Minas) e a FEMAP (Feira da Tecnologia Moveleira), têm contribuído para estreitar seus laços comerciais com outros polos brasileiros, distribuidores, varejistas e consumidores em geral, nacionais ou estrangeiros.

Segundo Arruda (2005), o maior salto ocorrido em exportações de móveis no Brasil, no primeiro bimestre de 2005, foi obtido pelo polo moveleiro de Ubá, cujas exportações saltaram de US\$ 1 milhão para US\$ 2,8 milhões, equivalentes a $173 \%$, com relação ao mesmo período do ano anterior. Nota-se, então, que o polo moveleiro de Ubá está num processo de progressiva abertura para o mercado externo e, para tanto, deve buscar fatores de competitividade que possam-lhe auxiliar nesse empreendimento. A certificação florestal pode ser uma das ferramentas utilizadas pelas empresas da indústria moveleira nacional para se diferenciar no mercado externo e, dessa forma, incrementar suas vendas.

A partir das observações anteriormente citadas, torna-se importante verificar qual seria o potencial da certificação florestal nesse polo. Assim, este trabalho teve como objetivo avaliar o potencial de implementação da certificação florestal no polo moveleiro de Ubá. Como objetivos específicos, pretendeu-se:

* avaliar a origem da madeira e seus derivados utilizados pelas empresas estudadas;

* avaliar o atendimento à política de porcentagens de matéria-prima certificada admitida pelos padrões de certificação; e

* avaliar a disposição dos empresários do polo em investir na obtenção da certificação florestal.

\section{MATERIAL E MÉTODOS}

Existem dois tipos de certificação florestal: a do manejo florestal e a de cadeia de custódia. Esta última certifica as indústrias que processam ou vendem produtos florestais, rastreando a matéria-prima desde a floresta até o consumidor. Esse tipo de certificação florestal é adotado pela indústria moveleira. Na época deste trabalho, não havia em Minas Gerais nenhuma empresa dessa indústria com a certificação de cadeia de custódia, o que aconteceu somente em meados de 2008, com a certificação de uma empresa moveleira da cidade de São Sebastião do Paraíso, que trabalha com móveis de pinus e eucalipto. 
Sabendo que existem empresas exportadoras no polo moveleiro de Ubá, considerou-se que as potencialmente interessadas na certificação seriam as que já possuíam alguma experiência com o processo de exportação. A relação dessas empresas foi obtida no Sindicato Intermunicipal das Indústrias de Marcenaria (Intersind), do polo moveleiro de Ubá, perfazendo um total de 20 empresas.

Para obter os dados desta pesquisa, elaborouse um questionário seguindo as orientações de Cervo e Bervian (2002) e Gil (1991). Segundo eles, de acordo com o tipo de pergunta pode-se classificá-la como fechada por número limitado de opções, ou aberta, sem restrições. Além disso, as perguntas devem conduzir facilmente às respostas de forma a não insinuarem outras colocações.

Antes de ser aplicado o questionário, este foi adequado segundo critérios preestabelecidos por auditores e especialistas na área e submetido, posteriormente, a um pré-teste em $15 \%$ das empresas.

Ao final, obtiveram-se total de 20 questionários respondidos, representando $100 \%$ das empresas que atendiam aos critérios preestabelecidos para o estudo.

Com relação aos dados referentes às respostas do questionário, usou-se a estatística descritiva, os quais estes foram organizados e sistematizados por meio de tabulação, utilizando planilha eletrônica.

Especificamente com relação à questão de cumprimento da política de porcentagens pelas empresas pesquisadas no polo, adotou-se a seguinte metodologia:

- empresas classificadas como cumpridoras plenamente da porcentagem exigida foram definidas como aquelas que utilizam apenas fornecedores com matéria-prima certificada, não restando dúvidas de que seu produto final principal cumpre os pré-requisitos para a certificação de cadeia de custódia;

- empresas classificadas como parcialmente cumpridoras da porcentagem foram definidas como as que não há certeza, em números, que tal porcentagem está sendo cumprida, pois se pode usar uma matériaprima certificada ou não;

- empresas classificadas como as que não atendem à porcentagem foram definidas como aquelas em que não há compra de matéria-prima certificada, o que significa que não haveria a possibilidade de reajustes na composição entre materiais certificados e não certificados.

\section{RESULTADOS E DISCUSSÃO}

A maioria das empresas pesquisadas $(75 \%)$ localizava-se no Município de Ubá. As demais estavam situadas nos seguintes municípios: Visconde do Rio Branco, Guidoval, Rodeiro e Tocantins, todos pertencentes ao polo.

As 20 empresas que atendiam aos critérios da pesquisa pertenciam a três categorias:

- Já exportavam, como no caso das empresas pertencentes à Associação dos Exportadores de Móveis de Ubá e Região (Movexport), representando 35\% delas, ou pelas ditas "independentes", por não estarem associadas a um consórcio de exportação (10\%).

- Exportaram apenas por um período de tempo, quando faziam parte da Movexport (10\%).

- Estavam em vias de iniciar seu processo de exportação, como no caso das empresas do consórcio recém-criado, "Minas Furniture” (45\%).

A maioria das empresas pesquisadas no polo, como se pode verificar, estava agrupada em consórcios com fins de exportação.

\subsection{Aspectos sociais e ambientais das empresas pesquisadas}

A certificação de cadeia de custódia exige apenas a comprovação da matéria-prima certificada ao longo do processo produtivo, desde a sua entrada até a confecção final do produto, que deve respeitar a política de porcentagens estabelecidas pelo sistema de certificação. Segundo Imaflora (2002), no entanto, no caso do sistema Forest Stewardship Council (FSC), existe tendência de as certificadoras incorporarem nas avaliações tanto os aspectos sociais (por exemplo, uso de equipamentos de proteção individual, cumprimento de leis trabalhistas, condições de trabalho) quanto os aspectos ambientais (por exemplo, tratamento de resíduos e controle de efluentes).

Dessa forma, pensando numa possível certificação no futuro, em que tais exigências sociais e ambientais pudessem estar incorporadas, procurou-se averiguar em quais desses pontos as empresas pesquisadas no polo já estavam atendendo ao mínimo exigido pela legislação e como estava o seu desempenho ambiental e social.

Sobre os resultados apresentados com relação aos aspectos ambientais e sociais, pode-se dizer que:

R. Árvore, Viçosa-MG, v.33, n.2, p.387-394, 2009 
a) nenhuma das empresas pesquisadas possuía a ISO 14001 (gestão do meio ambiente) ou, mesmo, a ISO 9001 (gestão da qualidade). Essa ausência pode ser explicada pela não exigência do mercado consumidor dessas empresas;

b) apenas parcela das empresas (25\%) cumpria as normas do Conselho de Política Ambiental (COPAM) e possuía licenciamento ambiental;

c) em $95 \%$ das empresas pesquisadas havia exaustores de pó, demonstrando que essas empresas estavam em conformidade com os requisitos estabelecidos pela legislação;

d) $40 \%$ das empresas efetuavam a queima de algum material;

e) $55 \%$ das empresas faziam tratamento de seus resíduos químicos;

f) em todas as empresas pesquisadas havia a Comissão Interna de Prevenção de Acidentes (CIPA), e seus funcionários utilizavam Equipamentos de Proteção Individual (EPIs);

g) em $55 \%$ das empresas existia um técnico em segurança do trabalho; e

h) cerca de $50 \%$ das empresas faziam um acompanhamento dos índices de número de acidentes no trabalho.

Assim, pode-se verificar que as empresas necessitam melhorar seu desempenho ambiental e social, pensando não somente na certificação de cadeia de custódia, mas também na contribuição para o desenvolvimento sustentável da atividade moveleira no polo de Ubá.

\subsection{Principais mercados das empresas pesquisadas}

Procurou-se abordar a questão relativa ao mercado dessas empresas do polo. Conhecer esse mercado pode trazer direcionamento atualmente é exigente ou não quanto à certificação florestal.

Pelos resultados, verificou-se que a maioria das empresas (85\%) tinha o mercado interno como o principal (Figura 1). Para todas elas, a Região Sudeste se configurava como o mercado consumidor interno principal de seus produtos, sendo importante destacar, também, a Região Nordeste (Figura 2).

- Com relação ao mercado externo, este era tido como o principal mercado de $15 \%$ das empresas pesquisadas, sendo o Chile o país mais citado (Figura 3).

R. Árvore, Viçosa-MG, v.33, n.2, p.387-394, 2009

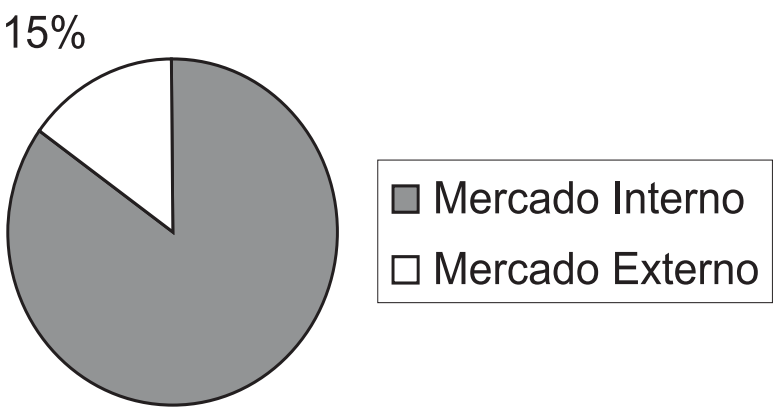

$85 \%$

Figura 1 - Principal mercado das empresas pesquisadas. Figure 1-Main market of the companies studied.

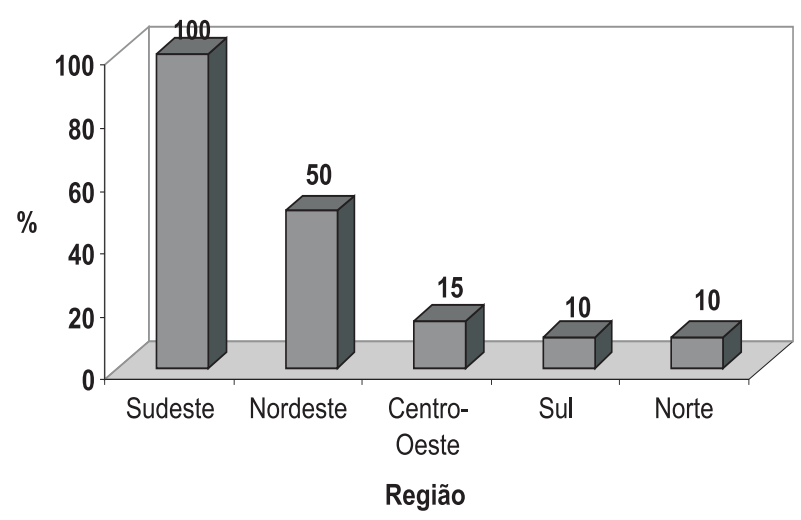

Figura 2 - Distribuição percentual do mercado nacional das empresas pesquisadas no polo moveleiro de Ubá, por região.

Figure 2-National market percent distribution of the furniture companies studied in Ubá, per region.

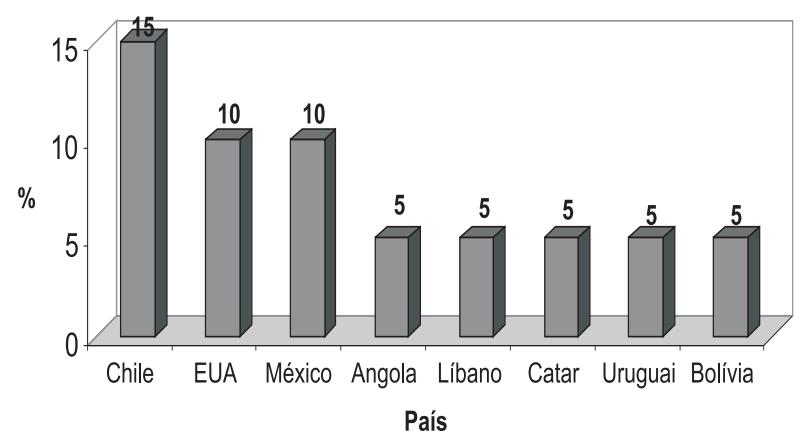

Figura 3 - Distribuição porcentual dos principais mercados externos das empresas pesquisadas no polo moveleiro de Ubá.

Figure 3 - Percent distribution of the main external markets of the furniture companies studied in Ubá. 
Sobre o atendimento a esse mercado latinoamericano, como no caso das empresas que vendem para o Chile, Garlipp e Maffeis (2000), citando os dados da Abimóvel, relataram que as exportações dos móveis brasileiros têm grande potencial de crescimento nesses mercados, considerando a influência da proximidade geográfica na redução do custo de transporte e o grau de competitividade da indústria brasileira em relação aos setores industriais desses países.

Sobre a exigência da certificação florestal nos países atendidos pelas empresas certificadas, pode-se inferir, apenas, que somente ocorria em alguns nichos de mercado dos Estados Unidos. Tradicionalmente, os países mais exigentes eram os da Europa, que não são atendidos pelo polo. Dessa forma, a certificação florestal é interessante para as empresas que pretendam entrar futuramente no mercado europeu.

Verificou-se, também, que as vendas para o mercado externo eram ocasionais. Muitas vezes, essas empresas só vendiam para o exterior quando "fechavam algum pedido" de determinado cliente. Entre um pedido e outro, podem, entretanto, decorrer vários meses.

\subsection{Principais produtos das empresas pesquisadas}

Nas empresas pesquisadas, os principais produtos, por faturamento, eram salas de jantar e móveis de dormitório (Figura 4).

Os móveis produzidos pelas empresas pesquisadas no polo moveleiro de Ubá são do tipo “populares”, atingindo número maior de consumidores. No entanto, segundo Alves (2005), os móveis das empresas da indústria moveleira que possuem a certificação de cadeia de custódia são mais direcionados a consumidores de determinados nichos de mercado e com maior poder aquisitivo.

Dessa forma, a certificação florestal pode estar mais relacionada com a exigência de poucos consumidores conscientes da necessidade de se obter um produto ambientalmente correto (e que podem pagar por isso) do que com a exigência de consumidores que compram um produto vendido em massa, mais relacionado com a necessidade de uso.

\subsection{Principais matérias-primas utilizadas pelas empresas pesquisadas}

Para conseguir a certificação de cadeia de custódia, uma empresa da indústria moveleira deve atender ao critério da rastreabilidade, garantindo que seu produto final cumpre a política de porcentagens estabelecidas pelo sistema de certificação. Para móveis, essa política representa, atualmente, a porcentagem mínima de $70 \%$ de material certificado no produto.

Procurou-se identificar quais matérias-primas entravam na composição do produto indicado pelas empresas pesquisadas e quais eram seus fornecedores. Verificou-se que a madeira e seus derivados constituem as principais matérias-primas dos móveis destas empresas, representando mais de $70 \%$ do produto final, em $82 \%$ dos casos (Figura 5).

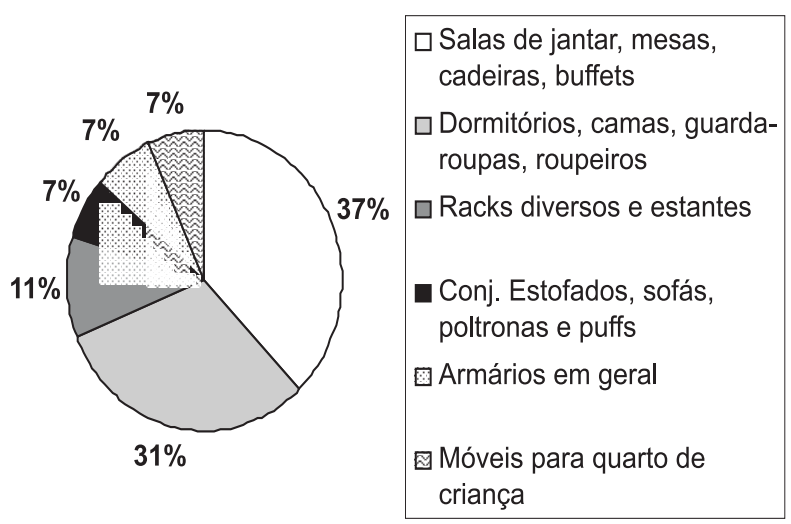

Figura 4 - Distribuição porcentual dos principais produtos, em termos de faturamento, das empresas pesquisadas no polo moveleiro de Ubá.

Figure 4-Percent distribution of the main products, in terms of profiting, of the furniture companies studied in Ubá.

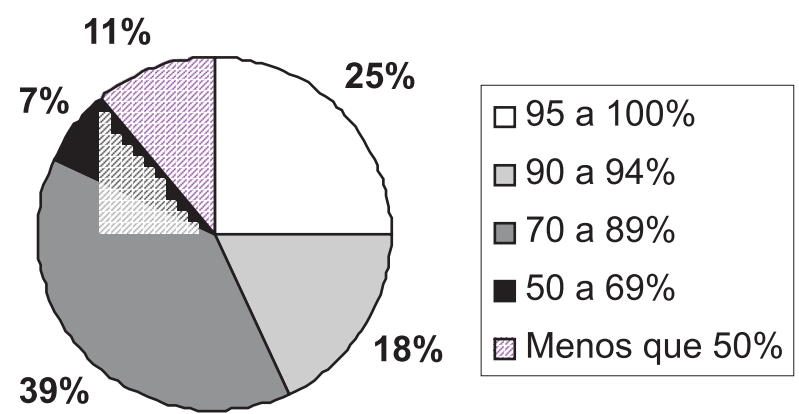

Figura 5 - Composição porcentual da madeira e seus derivados nos principais produtos das empresas pesquisadas no polo moveleiro de Ubá.

Figure 5-Percent composition of wood and its by-products in the major products made by the studied furniture companies in Ubá.

R. Árvore, Viçosa-MG, v.33, n.2, p.387-394, 2009 
Esse resultado vai de encontro ao estudo realizado por Fernandes e Oliveira Júnior (2002). Segundo eles, com relação ao tipo de produto do polo moveleiro de Ubá, a produção de móveis de madeira, em especial móveis residenciais, assume maior destaque quanto ao número de empresas e, consequentemente, empregos gerados.

Com relação às principais matérias-primas utilizadas nos produtos indicados por essas empresas pesquisadas, destacam-se o aglomerado (usado por 60\% das empresas), o MDF (55\% delas) e a madeira maciça ( $30 \%$ delas).

Esse fator favorece uma possível certificação florestal nessa região, pois já existem fornecedores desses painéis certificados, ou seja, um elo da cadeia de custódia já está certificado. Alguns fatores podem influenciar consideravelmente a participação da madeira maciça na composição dos móveis. Um deles é o fato de estar sendo implementada uma série de ações pelo Estado, por meio de seus órgãos ambientais reguladores, no sentido de minimizar o desmatamento na Amazônia. Com isso, o mercado já está refletindo a diminuição da falta da madeira, com alta considerável em seu preço. Às empresas caberá substituir a madeira nativa pelas chapas (MDF, aglomerado e outras) ou, então, pelas madeiras oriundas de reflorestamento, principalmente pelo pinus e eucalipto. Sobre o eucalipto, conforme estudo de Teixeira (2005), no polo de Ubá há, ainda, muita falta de informação sobre sua utilização e métodos adequados de manuseio, além de dificuldade de acesso à matéria-prima.

\subsection{Interesse das empresas e cumprimento da política de porcentagens}

Para conhecer o interesse dessas empresas numa futura certificação de cadeia de custódia, perguntou-se:

"Mesmo que seus clientes atuais e,ou, potenciais não sejam exigentes quanto à certificação florestal atualmente, mas, estando os custos envolvidos dentro de sua realidade financeira, a empresa estaria disposta a buscá-la?"

Como resultado dessa pergunta, $90 \%$ das empresas responderam que "sim", alegando tratar-se de importante instrumento para alavancar vendas, constituindo-se num diferencial competitivo no mercado.

Pode-se afirmar que a certificação de cadeia de custódia despertou o interesse das empresas estudadas.
Tornou-se necessário, no entanto, avaliar se essas empresas já estavam atendendo à política de porcentagens admitida pelo sistema de certificação.

Para as empresas moveleiras, de acordo com o Imaflora (2002) o controle é feito por produto, e essas empresas estão na classe de produtos montados. A política de porcentagens adotada, nesse caso, é que pelo menos $70 \%$ do volume da madeira contida no produto deve ter sua origem certificada.

Pelos resultados, verificou-se que $85 \%$ das empresas pesquisadas compravam matéria-prima certificada e atendiam, plena ou parcialmente, à política de porcentagens (Figura 6).

- Nas empresas pesquisadas que atendiam parcialmente à política de porcentagens, ocorre a compra de matéria-prima de fornecedores certificados e nãocertificados. Para essas empresas buscarem a certificação de cadeia de custódia, elas necessitariam utilizar a matéria-prima de seus fornecedores certificados em pelo menos $70 \%$ do volume de madeira, de forma a garantir o percentual mínimo exigido. A matéria-prima dos outros fornecedores nãocertificados poderia, então, entrar na composição restante. Assim, teriam que efetuar ajustes no uso da matéria-prima para se adequar às exigências do FSC. Poderiam, também, estabelecer linhas de produtos certificados e não-certificados.

Outra forma, mas que não dependeria da ação direta das empresas, seria que seus fornecedores de matériaprima não-certificada buscassem a certificação de cadeia de custódia. Essas empresas, como clientes, poderiam pressionar pela certificação dos seus fornecedores.

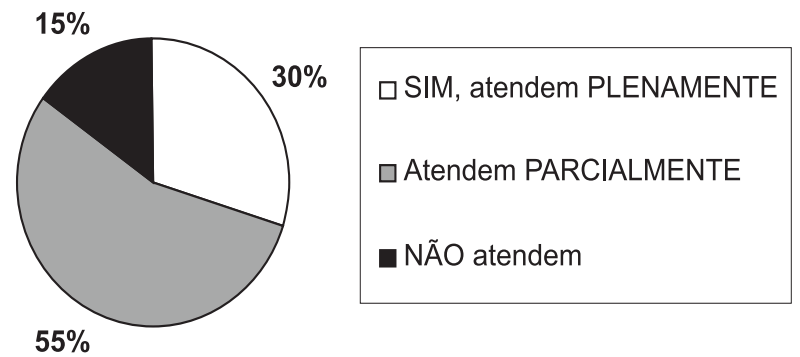

Figura 6 - Distribuição porcentual das empresas pesquisadas no polo e sua situação quanto ao atendimento das porcentagens de matéria-prima certificadas exigidas pelo FSC.

Figure 6-Percent distribution of the furniture center companies and their situation concerning meeting certified raw material percentages demanded by the FSC. 
As empresas que trabalhavam, especificamente, com salas de jantar tinham por característica o uso da madeira maciça em seus produtos (na cadeira, principalmente) que, geralmente, não vinham de fornecedor certificado, como era o caso dos painéis reconstituídos. Para superar esse gargalo será necessário buscar um fornecedor de madeira maciça certificada ou, então, esperar maior oferta dessa madeira no mercado.

Pelos resultados gerais obtidos, em termos de atendimento à política de porcentagens de matériaprima para a certificação de cadeia de custódia, podese dizer que essa seria aplicável à maioria das empresas estudadas no polo moveleiro de Ubá (85\%), evidentemente com algumas adaptações de uso de matéria-prima em algumas. Aliando esses resultados com o interesse manifestado por $90 \%$ das empresas e com o fato de estas empresas já estarem vendendo para o mercado externo, pode-se inferir que a certificação de cadeia de custódia no polo pode ser considerada viável, pelo menos em médio prazo.

\section{CONCLUSÕES}

Pelos resultados apresentados neste trabalho, pode-se concluir que:

- O mercado externo não representava o principal mercado das empresas pesquisadas, visto que suas exportações eram ocasionais.

- Os países para os quais as empresas exportavam não eram tradicionalmente exigentes quanto à certificação florestal.

- As exportações do polo vinham aumentado e poderiam demandar a busca da certificação florestal caso optassem assim por atingir mercados mais exigentes, como o europeu.

- Uma possível implementação de a certificação de cadeia de custódia pelas empresas seria facilitada pelo fato de a maioria delas já adquirir parte da matériaprima certificada.

- A certificação de cadeia de custódia no polo pode ser considerada viável, pelo menos no médio prazo.

- A certificação florestal pode ser excelente oportunidade de valorização e diferenciação do polo.

\section{REFERÊNCIAS}

ALVES, R. R. A certificação florestal na indústria moveleira nacional com ênfase no Pólo de Ubá, MG. 2005. 112 f. Dissertação (Mestrado em Ciência Florestal) Universidade Federal de Viçosa, Viçosa, MG, 2005.

ALVES, R. R, et al. Certificação florestal na visão gerencial e estratégica do Pólo Moveleiro de Ubá, MG. Revista Cerne, v.13, n.1, p.117-122, 2007.

ARRUDA, G. Embarques sobem no $1^{\circ}$ bimestre. Gazeta Mercantil, 29 mar. 2005. Gazeta do Brasil. p.14.

ASSOCIAÇÃO BRASILEIRA DAS INDÚSTRIAS DO MOBILIÁRIO - ABIMÓVEL. Panorama do setor moveleiro no Brasil - Junho/ 2004. São Paulo: 2004. 53p.

CERVO, A. L.; BERVIAN, P. A. Metodologia científica. 5.ed. São Paulo: Prentice Hall, 2002. 242p.

FERNANDES, C. L. L.; OLIVEIRA JÚNIOR, R. H. O. Cluster no setor moveleiro: um estudo das potencialidades da região de Ubá (MG). Belo Horizonte: UFMG, 2002. 26 p.

GARLIPP, R. C. Recursos Forestales Brasil. Santiago, Chile: FAO - Food and Agriculture Organization of the United Nations, 2001. 58p.

GARLIPP, R. C.; MAFFEIS, A. Competitividade da cadeia produtiva de madeira e móveis. Revista Silvicultura, n. 83, p.16-21, 2000.

GIL, A. C. Como elaborar projetos de pesquisa. São Paulo: Atlas, 1991. 176p.

INSTITUTO DE MANEJO E CERTIFICAÇÃO FLORESTAL E AGRÍCOLA - IMAFLORA

Manual de certificação de cadeia de custódia no sistema do Forest Stewardship Council - FSC. Piracicaba: 2002. 50p.

JACOVINE, L. A. G. et al. Processo de implementação da certificação florestal nas empresas moveleiras nacionais. Revista Árvore, v.30, n.6, p.961-968, 2006a.

R. Árvore, Viçosa-MG, v.33, n.2, p.387-394, 2009 
JACOVINE, L. A. G. et al. Certificação florestal na visão gerencial e estratégica da indústria moveleira nacional. Revista Semina - Ciências Agrárias, v.27, n.3, p.363-374, 2006b.

NARDELLI, A. M. B.; GRIFFITH, J. J. Modelo teórico para compreensão do ambientalismo empresarial do setor florestal brasileiro. Revista Árvore, v.27, n.6, p.855-869, 2003.
SUITER FILHO, W. Certificação florestal: ferramenta para múltiplas soluções. Revista Ação Ambiental, v.3, n.13, p.16-18, 2000.

TEIXEIRA, T. O. B. A percepção sobre o uso da madeira de eucalipto pelos fabricantes do pólo moveleiro de Ubá, MG. 2005. 59f. Dissertação (Mestrado em Ciência Florestal) - Universidade Federal de Viçosa, Viçosa, MG, 2005. 